\title{
Increasing the oxidation power of TCNQ by coordination of the fluorinated Lewis acid $B\left(\mathrm{C}_{6} \mathrm{~F}_{5}\right)_{3}$
}

Paul Anton Albrecht, ${ }^{a}$ Susanne Margot Rupf, ${ }^{a}$ Malte Sellin ${ }^{\mathrm{a}, \mathrm{b}}$, Johanna Schlögl, ${ }^{\text {a }}$ Sebastian Riedel ${ }^{\mathrm{a}}$ and Moritz Malischewski*a

The oxidation power of the cyanocarbon TCNQ (tetracyanoquinodimethane) can be significantly increased to approximately $E=+0.9 \mathrm{~V}$ vs. $\mathrm{Cp}_{2} \mathrm{Fe}$ by coordination of up to four equivalents of the strong fluorinated Lewis acid $B\left(\mathrm{C}_{6} \mathrm{~F}_{5}\right)_{3}$. Thianthrene and tris $(4-$ bromophenyl)amine were oxidized to the corresponding radical cations. Dianionic $\left[\mathrm{TCNQ} \cdot 4 \mathrm{~B}\left(\mathrm{C}_{6} \mathrm{~F}_{5}\right)_{3}\right]^{2-}$ was formed upon reduction with two equivalents of ferrocene or decamethylcobaltocene.

Strong one-electron oxidizing agents are of great synthetic utility, providing access to highly reactive target molecules. However, it is challenging to find a good balance between oxidation power, absence of side reactions, ease of handling and availability of the reagents. For example, inorganic fluorine compounds like (gaseous) $\mathrm{AsF}_{5}$ or metal hexafluorides are extremely powerful oxidants e.g. in liquid $\mathrm{SO}_{2}$, but they can often not be handled in standard laboratories. ${ }^{1,2}$ In their seminal review on chemical redox agents, Connelly and Geiger discussed more popular reagents, e.g. $\mathrm{Ag}^{+}$and $\mathrm{NO}^{+}$, ferrocenium and triarylaminium salts. ${ }^{3}$ They classified all reagents with redox potentials $E>+0.8 \mathrm{~V}$ vs. $\mathrm{Cp}_{2} \mathrm{Fe}$ as very strong oxidants. However, it has to be stated, that especially in combination with transition metal complexes, the use of $\mathrm{Ag}^{+}$or $\mathrm{NO}^{+}$can lead to side reactions. ${ }^{4,}{ }^{5}$ Interestingly, the oxidation power of $\mathrm{Ag}^{+}$can be significantly increased in combination with elemental halogens $X_{2}$ $(\mathrm{X}=\mathrm{Cl}, \mathrm{Br}, \mathrm{I})$, since the formation of insoluble AgX provides an additional driving force. ${ }^{6,7}$ Another highly useful system was developed by Poleschner. By using $\mathrm{XeF}_{2}$ in combination with fluoride acceptors $\left(\mathrm{BF}_{3} \cdot \mathrm{Et}_{2} \mathrm{O}, \mathrm{Me}_{3} \mathrm{SiOTf}\right.$, etc.) different weakly-coordinating anions can be introduced. ${ }^{8}$ Jenne demonstrated the very high oxidation power of the boron cluster radical $\mathrm{Me}_{3} \mathrm{NB}_{12} \mathrm{Cl}_{11}$, however its multi-step synthesis seems to have prevented widespread use by other groups. ${ }^{9}$ The same is true for Michl's $\mathrm{CB}_{11} \mathrm{Me}_{12}$ or a perfluorinated ammoniumyl cation of the Krossing group. ${ }^{10,11}$ In contrast to this, cyanocarbons, although mild oxidants, are often commercially available and air-stable. Due to the electronwithdrawing character of the cyano groups, neutral cyanocarbons are molecules with high electron affinities. ${ }^{12}$ Consequently, they easily form radical anions (or even dianions) of significant stability

\footnotetext{
a. Freie Universität Berlin, Institute of Chemistry and Biochemistry, Fabeckstr. 34-36, 14195 Berlin, E-mail: moritz.malischewski@fu-berlin.de

b. Albert-Ludwigs-Universität Freiburg, Institute of Inorganic and Analytical

Chemistry, Albertstraße 21, 79104 Freiburg
}

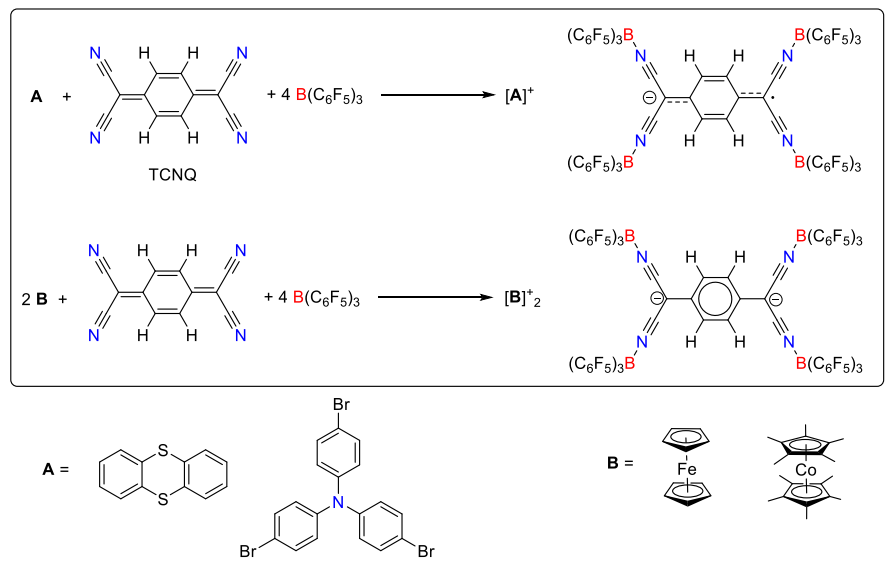

Scheme 1. Substrate scope of the new oxidation system TCNQ $+4 B\left(C_{6} F_{5}\right)_{3}$.

when treated with a reducing agent. This has led to a plethora of applications, e.g. in molecular magnetism ${ }^{13,14}$ and for the doping of organic polymers. ${ }^{15}$ Since tetracyanoquinodimethane (TCNQ) is only a mild oxidant (first reduction potential $E=-0.30 \mathrm{~V}$, second reduction potential $E=-0.88 \mathrm{~V}$ vs. $\left.\mathrm{Cp}_{2} \mathrm{Fe}\right)^{3,16,17}$ we assumed that its electron affinity could be increased and manipulated by coordination of Lewis acids to the terminal nitrogen atoms. ${ }^{18}$

Tris(pentafluorophenyl)boron is a commercially available and potent Lewis acid. ${ }^{19}$ It has a high affinity for hard donor atoms, e.g. nitrogen, but is typically non-oxidizing. ${ }^{20,21}$ Indeed, the reduction to its radical anion is only achieved at redox potentials below $E=-1.7 \mathrm{~V}$ vs. $\mathrm{Cp}_{2} \mathrm{Fe}^{22-24}$ Interestingly, it has been shown by Stephan and Erker that

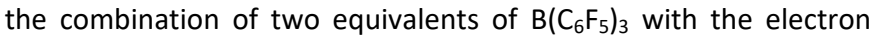
acceptor $p$-benzoquinone $\mathrm{C}_{6} \mathrm{H}_{4} \mathrm{O}_{2}$ is able to oxidize decamethylferrocene to its cation. ${ }^{25}, 26$ Depending on the stoichiometry $\left[\mathrm{C}_{6} \mathrm{H}_{4} \mathrm{O}_{2} \cdot 2 \mathrm{~B}\left(\mathrm{C}_{6} \mathrm{~F}_{5}\right)_{3}\right]^{-/ 2-}$ mono- or dianions are obtained. By choosing other Lewis acids, the oxidation power of the system can be tuned. ${ }^{27}$ Another example for cooperative effects between electron acceptors and fluorinated Lewis acids is the combination of dioxygen with two equivalents of $B\left(C_{6} F_{5}\right)_{3}$ which is even able to oxidize air-stable ferrocene to ferrocenium under formation of $\left[\left(\mathrm{C}_{6} \mathrm{~F}_{5}\right)_{3} \mathrm{BOOB}\left(\mathrm{C}_{6} \mathrm{~F}_{5}\right)_{3}\right]^{2-}$ dianions. ${ }^{28}$ 


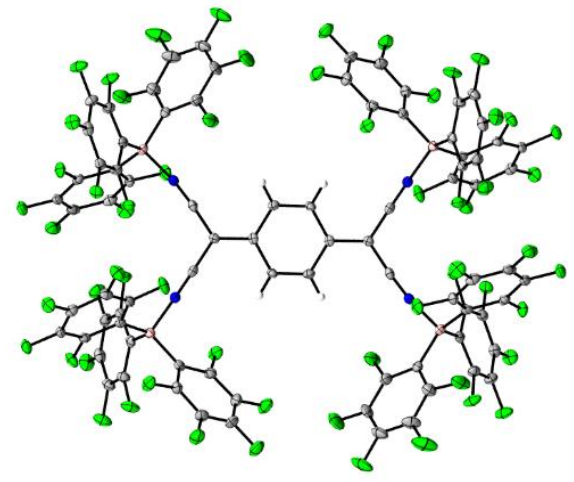

Figure 1. Molecular structure of the radical anion in $\left[\left(\mathrm{C}_{6} \mathrm{H}_{4}\right)_{2} \mathrm{~S}_{2}\right]^{+}$ [TCNQ.4 B $\left.\left(\mathrm{C}_{6} \mathrm{~F}_{5}\right)_{3}\right]^{-}$, thermal ellipsoids shown with $50 \%$ probability, colour code: hydrogen white, carbon grey, fluorine green, nitrogen blue, boron rosé.

In order to develop a new oxidizing system, we investigated the combination of TCNQ with four equivalents of $B\left(\mathrm{C}_{6} \mathrm{~F}_{5}\right)_{3}$ (Scheme 1). Although we were not able to isolate a neutral 1:4 adduct, this mixture is strongly oxidizing in weakly-basic solvents like dichloromethane or o-dichlorobenzene. Both tris(4bromophenyl)amine $\left(E=+0.70 \mathrm{~V}\right.$ vs. $\left.\mathrm{Cp}_{2} \mathrm{Fe}\right)$ and thianthrene $(E=$ $+0.86 \mathrm{~V}$ vs. $\left.\mathrm{Cp}_{2} \mathrm{Fe}\right)$ are instantaneously oxidized to their corresponding (blue / violet) radical cations, ${ }^{3}$ forming monoanionic [TCNQ.4 B $\left.\left(\mathrm{C}_{6} \mathrm{~F}_{5}\right)_{3}\right]^{-}$as the counterion. Both $\left[\mathrm{N}\left(\mathrm{C}_{6} \mathrm{H}_{4} \mathrm{Br}\right)_{3}\right]^{+}[\mathrm{TCNQ} \cdot 4$ $\left.\mathrm{B}\left(\mathrm{C}_{6} \mathrm{~F}_{5}\right)_{3}\right]^{-} \cdot 4 o-\mathrm{C}_{6} \mathrm{H}_{4} \mathrm{Cl}_{2}$ and $\left[\left(\mathrm{C}_{6} \mathrm{H}_{4}\right)_{2} \mathrm{~S}_{2}\right]^{+}\left[\mathrm{TCNQ} \cdot 4 \mathrm{~B}\left(\mathrm{C}_{6} \mathrm{~F}_{5}\right)_{3}\right]^{-}$could be structurally characterized via single crystal X-ray diffraction (Fig. 1). Due to the 4:1 stoichiometry, all cyano groups are coordinated to the Lewis acidic boron centers. Consequently, no potential nitrogen donor sites are present, ${ }^{29}$ resulting in a new, large weaklycoordinating monoanion with 60 fluorine atoms involved. To estimate the reduction potential that is needed to reduce the radical monoanions to diamagnetic dianions, we successfully used two equivalents of ferrocene per TCNQ. Their oxidation to ferrocenium showed the significant oxidation power of the radical monoanions. Additionally, this indicates potential stability of the dianion against dioxygen. Nevertheless these adducts are sensitive to water and Lewis bases. Despite its low solubility in dichloromethane, the structure of $\left[\mathrm{Cp}_{2} \mathrm{Fe}^{+}{ }_{2}\left[\mathrm{TCNQ} \cdot 4 \mathrm{~B}\left(\mathrm{C}_{6} \mathrm{~F}_{5}\right)_{3}\right]^{2-} \cdot 2 \mathrm{CH}_{2} \mathrm{Cl}_{2}\right.$ could be determined via single-crystal $\mathrm{X}$-ray diffraction. To prepare a salt with diamagnetic cations and anions (and better solubility), two equivalents of decamethylcobaltocene were successfully used as reducing agent. Correspondingly, the structure of $\left[\mathrm{Cp}_{2}{ }_{2} \mathrm{Co}\right]_{2}^{+}\left[\mathrm{TCNQ} \cdot 4 \mathrm{~B}\left(\mathrm{C}_{6} \mathrm{~F}_{5}\right)_{3}\right]^{2-} \cdot 2 \mathrm{CH}_{2} \mathrm{Cl}_{2}$ was also determined. In all four characterized salts, the structures of the cations are in

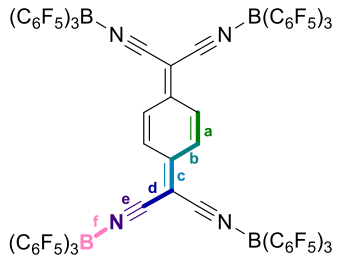

not aromatic

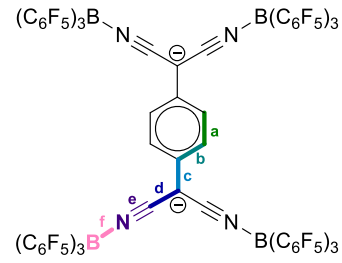

aromatic
Figure 2. Lewis formulas of $\left[\mathrm{TCNQ} \cdot 4 \mathrm{~B}\left(\mathrm{C}_{6} \mathrm{~F}_{5}\right)_{3}\right]$ (left) and $\left[\mathrm{TCNQ} \cdot 4 \mathrm{~B}\left(\mathrm{C}_{6} \mathrm{~F}_{5}\right)_{3}\right]^{2-}$ (right) and assignment of the labels for the discussion of bond lengths.

accordance with literature reports and will not be further discussed here. $\mathrm{H} \cdots \mathrm{F}$ contacts between cations and anions are in the range of 2.4-2.7 $\AA$ and can therefore be considered as weak hydrogen bond contacts.

In general the mono- and dianions look very similar on the first sight since the four cyano groups are slightly tilted out of the plane of the central six-membered ring. However, several characteristic trends regarding specific bond lengths of the TCNQ core can be noticed. Neutral TCNQ displays significant variations regarding the $\mathrm{C}-\mathrm{C}$ bond lengths in its six-membered ring due to its quinoidal nature. However, upon reduction to its mono- and (aromatic) dianion, these differences are becoming less pronounced..$^{30}$ The same trend is observed for the adducts [TCNQ.4 B $\left.\left(\mathrm{C}_{6} \mathrm{~F}_{5}\right)_{3}\right]^{0} /^{-/ 2-}$ (Fig. 2, Tab. 1). The six-membered ring in $\left[\left(\mathrm{C}_{6} \mathrm{H}_{4}\right)_{2} \mathrm{~S}_{2}\right]^{+}\left[\mathrm{TCNQ} \cdot 4 \mathrm{~B}\left(\mathrm{C}_{6} \mathrm{~F}_{5}\right)_{3}\right]^{-}$is characterized by two short $(1.359(3) \AA)$ and four long bonds (1.414(3)-1.426(3) $\AA$. The $C-C(C N)_{2}$ bond has a length of 1.426(3) $\AA$. In $\left[\mathrm{Cp}_{2} \mathrm{Fe}\right]^{+}{ }_{2}\left[\mathrm{TCNQ} \cdot 4 \mathrm{~B}\left(\mathrm{C}_{6} \mathrm{~F}_{5}\right)_{3}\right]^{2-} \cdot 2 \mathrm{CH}_{2} \mathrm{Cl}_{2}$ the $\mathrm{C}-\mathrm{C}$ bonds of the sixmembered ring of TCNQ are all very similar in length (1.383(2)$1.396(2) \AA)$, indicating a more effective electron delocalization. The corresponding $\mathrm{C}-\mathrm{C}$ bond to the $\mathrm{C}(\mathrm{CN})_{2}$ group is longer $(1.480(2) \AA)$ than in the monoanion. In the ferrocenium salt the average $\mathrm{C} \equiv \mathrm{N}$ bond length $(1.149(2) \AA)$ is very similar to the corresponding value of the thianthrenium salt (1.145(3) $\AA$ ). The changes of the B-N bond lengths are more significant: $1.559(2) \AA$ in the dianion compared to $1.584(3) \AA$ in the monoanion, indicating a stronger donor-acceptor interaction in the former.

Table 1. Experimental (all four crystal structures) and calculated (B3LYP-GD3BJ/Def2-SVP) bond lengths in $\AA$ for $\left[\mathrm{TCNQ}_{\mathrm{C}} \cdot 4 \mathrm{~B}\left(\mathrm{C}_{6} \mathrm{~F}_{5}\right)_{3}\right]^{0 /-/ 2-}$, labels a to $f$ according to Figure 2.

\begin{tabular}{|c|c|c|c|c|c|}
\hline Bond & $\begin{array}{l}{\left[\mathrm{TCNQ} \cdot 4 \mathrm{~B}\left(\mathrm{C}_{6} \mathrm{~F}_{5}\right)_{3}\right]} \\
\text { calculated }\end{array}$ & $\begin{array}{l}{\left[\mathrm{TCNQ} \cdot 4 \mathrm{~B}\left(\mathrm{C}_{6} \mathrm{~F}_{5}\right)_{3}\right]^{-}} \\
\text {calculated }\end{array}$ & $\begin{array}{l}{\left[\mathrm{TCNQ} \cdot 4 \mathrm{~B}\left(\mathrm{C}_{6} \mathrm{~F}_{5}\right)_{3}\right]^{-}} \\
\text {experimental }\end{array}$ & $\begin{array}{l}{\left[\mathrm{TCNQ} \cdot 4 \mathrm{~B}\left(\mathrm{C}_{6} \mathrm{~F}_{5}\right)_{3}\right]^{2-}} \\
\text { calculated }\end{array}$ & $\begin{array}{l}{\left[\mathrm{TCNQ} \cdot 4 \mathrm{~B}\left(\mathrm{C}_{6} \mathrm{~F}_{5}\right)_{3}\right]^{2-}} \\
\text { experimental }\end{array}$ \\
\hline a & $1.358-1.365$ & $1.371-1.378$ & $1.359(3)-1.364(6)$ & 1.391-1.394 & $1.383(2)-1.388(2)$ \\
\hline$b$ & $1.440-1.444$ & $1.425-1.426$ & $1.411(6)-1.426(6)$ & $1.406-1.407$ & $1.396(2)-1.399(2)$ \\
\hline c & $1.401-1.402$ & $1.431-1.433$ & $1.426(6)-1.431(3)$ & $1.477-1.480$ & $1.470(2)-1.480(2)$ \\
\hline$d$ & $1.412-1.416$ & $1.401-1.405$ & $1.397(6)-1.405(6)$ & $1.383-1.386$ & $1.382(2)-1.385(2)$ \\
\hline e & $1.151-1.154$ & $1.154-1.156$ & $1.140(6)-1.145(3)$ & $1.164-1.166$ & $1.147(2)-1.151(2)$ \\
\hline
\end{tabular}



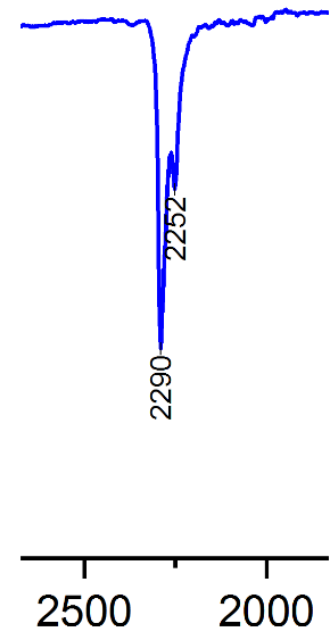
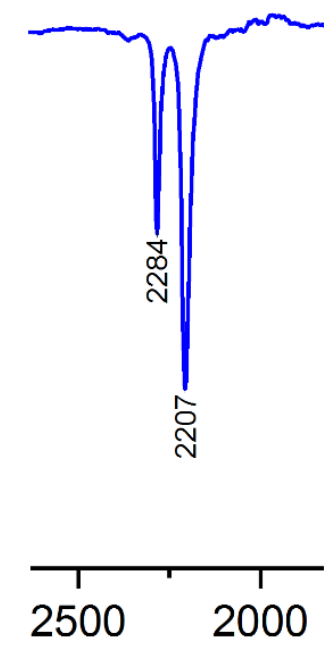

Figure 3. Region of $\tilde{v}(\mathrm{C} \equiv \mathrm{N})$ vibrations in the IR spectra of $\left[\left(\mathrm{C}_{6} \mathrm{H}_{4}\right)_{2} \mathrm{~S}_{2}\right]^{+}$ $\left[\mathrm{TCNQ} \cdot 4 \mathrm{~B}\left(\mathrm{C}_{6} \mathrm{~F}_{5}\right)_{3}\right]^{-}$(left) and $\left[\mathrm{Cp}_{2} \mathrm{Fe}^{+}{ }_{2}\left[\mathrm{TCNQ} \cdot 4 \mathrm{~B}\left(\mathrm{C}_{6} \mathrm{~F}_{5}\right)_{3}\right]^{2-}\right.$ (right).

Quantum-chemical calculations at the DFT level B3LYP-GD3BJ/Def2SVP have been performed to evaluate the structure and the vibrational frequencies of the neutral, mono- and dianionic 4:1 adducts between $B\left(C_{6} F_{5}\right)_{3}$ and TCNQ. They confirm that, upon reduction, the $\mathrm{C}-\mathrm{C}$ bond lengths of the six-membered ring become less variable. Additionally, a slight increase of $\mathrm{C} \equiv \mathrm{N}$ bond lengths is predicted upon reduction of the neutral species to the mono- and dianion ( $1.152 \AA \rightarrow 1.156 \AA \rightarrow 1.165 \AA$ ). Principally, one would expect a decrease of the computed $\tilde{v}(\mathrm{C} \equiv \mathrm{N})$ frequency for the reduced species. In general, four different $v(\mathrm{C} \equiv \mathrm{N})$ vibrations are predicted within the range of $2220-2350 \mathrm{~cm}^{-1}$. Upon reduction, the red-shift of the symmetric $\tilde{v}(\mathrm{C} \equiv \mathrm{N})$ vibration (which is highest in energy) is relatively little pronounced in the series $(2348 \rightarrow 2345 \rightarrow 2317$ $\left.\mathrm{cm}^{-1}\right)$. In contrast, the shift of the antisymmetric $\tilde{v}(\mathrm{C} \equiv \mathrm{N})$ vibration (which is lowest in energy) is much more pronounced $(2311 \rightarrow 2290$ $\rightarrow 2221 \mathrm{~cm}^{-1}$ ). Indeed, the experimental IR spectra of salts that contain the monoanions have two bands at 2290 and $\approx 2250 \mathrm{~cm}^{-1}$, while two bands at 2284 and $\approx 2205 \mathrm{~cm}^{-1}$ are observed for the dianion (Fig. 3). The widening of the range of $\tilde{v}(C \equiv N)$ frequencies upon reduction is consequently both experimentally and computationally found. Attempts to measure Raman spectra of the products were unsuccessful due to decomposition or intense fluorescence.

Based on DFT calculations (B3LYP-GD3BJ/Def2-SVP) the adiabatic electron affinities of the neutral adduct was estimated to be 583 $\mathrm{kJ} \cdot \mathrm{mol}^{-1}(6.04 \mathrm{eV})$. The reduction of the corresponding monoanion to the dianion is also highly favourable $\left(310 \mathrm{~kJ} \cdot \mathrm{mol}^{-1}, 3.21 \mathrm{eV}\right)$. In comparison, free TCNQ has an experimental electron affinity of 3.38 $\mathrm{eV} .{ }^{31}$ Consequently, the coordination of Lewis acids clearly increases its oxidation power and underlines our cooperativity concept for such systems.

Beyond that quantum-chemical characterization the $\left[\mathrm{Cp}_{2}{ }_{2} \mathrm{Co}\right]_{2}^{+}$ [TCNQ.4 B $\left.\left(\mathrm{C}_{6} \mathrm{~F}_{5}\right)_{3}\right]^{2-}$ had sufficient solubility in $\mathrm{CD}_{2} \mathrm{Cl}_{2}$ to allow its characterization via multinuclear NMR spectroscopy. Two signals in the ${ }^{1} \mathrm{H}-\mathrm{NMR}$ can be assigned to the TCNQ protons ( $\delta=6.82 \mathrm{ppm}$ ) as well as the methyl protons of decamethylcobaltocenium $(\delta=1.65$ ppm). In the ${ }^{11} \mathrm{~B}$ NMR spectrum a broad signal at $\delta=-11.5 \mathrm{ppm}$ is assigned to the tetracoordinate boron atoms in $\left[\mathrm{TCNQ} \cdot 4 \mathrm{~B}\left(\mathrm{C}_{6} \mathrm{~F}_{5}\right)_{3}\right]^{2-}$ which is also in agreement with other nitrogen-containing adducts. ${ }^{32}$ For example, $\left[\mathrm{CH}_{3} \mathrm{CN} \cdot \mathrm{B}\left(\mathrm{C}_{6} \mathrm{~F}_{5}\right)_{3}\right]$ has a ${ }^{11} \mathrm{~B} \mathrm{NMR}$ shift of $-10.3 \mathrm{ppm}$ (in $\left.\mathrm{C}_{6} \mathrm{D}_{6}\right) .{ }^{21}$ In comparison the ${ }^{11} \mathrm{~B}$ NMR shift of uncoordinated $\mathrm{B}\left(\mathrm{C}_{6} \mathrm{~F}_{5}\right)_{3}$ is observed at $+59.2 \mathrm{ppm}^{33}$ In the ${ }^{19} \mathrm{~F}$ NMR three main signals are observed for the meta, para and ortho fluorine atoms in the $\mathrm{C}_{6} \mathrm{~F}_{5}$ rings $\delta=-165.4,-159.3$ and $-134.8 \mathrm{ppm})$. These signals are slightly shifted in comparison to uncoordinated $\mathrm{B}\left(\mathrm{C}_{6} \mathrm{~F}_{5}\right)_{3}(\delta=-161.3,-144.2$ and $-128.4 \mathrm{ppm})$. Additionally, it was possible to find and assign almost all signals in the ${ }^{13} \mathrm{C}$ NMR spectrum. The decamethylcobaltocenium cation gives two signals at $\delta=8.2$ and $94.6 \mathrm{ppm}$ which is in agreement with literature values. ${ }^{34}$ For the central TCNQ moiety in [TCNQ.4 B $\left.\left(\mathrm{C}_{6} \mathrm{~F}_{5}\right)_{3}\right]^{2-}$ as well as for the pentafluorophenyl rings four signals are each expected. However, only seven peaks could be detected. The proton-decoupled ${ }^{13} \mathrm{C} N \mathrm{NR}$ spectrum displays three doublets for the fluorine-bound carbon atoms of the pentafluorophenyl rings $(\delta=148.6 ; 140.4$ and 137.6 $\mathrm{ppm})$. Additionally, one broad signal at $\delta=118.3 \mathrm{ppm}$ was observed. These signals are slightly shifted in comparison to free $\mathrm{B}\left(\mathrm{C}_{6} \mathrm{~F}_{5}\right)_{3}(\delta=$ 149.1 (ortho), 145.8 (para), 138.3 (meta) and 113.8 (ipso) ppm). ${ }^{33}$ Two additional signals at $\delta=126.0$ and $123.1 \mathrm{ppm}$ belong clearly to the aromatic TCNQ core of the dianion. In the uncomplexed neutral TCNQ the chemical shifts differ more significantly: $\delta=132.6$ and $151.7 \mathrm{ppm}$. For uncomplexed TCNQ the chemical shift of the cyano group is $\delta=112.6 \mathrm{ppm}^{35}$ However, no corresponding signal was found. Interestingly, one signal of the $\left[\mathrm{TCNQ} \cdot 4 \mathrm{~B}\left(\mathrm{C}_{6} \mathrm{~F}_{5}\right)_{3}\right]^{2-}$ dianion is strongly high-field shifted: the carbon atom of the TCNQ moiety that is bound to the two cyano groups. Due to some carbanion character, the signal is located at $\delta=30.5 \mathrm{ppm}$. In comparison, the same carbon resonates at $\delta=90.8 \mathrm{ppm}$ in free TCNQ.

Additionally, EPR spectroscopy at room temperature in dichloromethane was used to prove that electron transfer between the diamagnetic starting materials has taken place. Three experiments were performed: TCNQ with 4 equivalents of $B\left(C_{6} F_{5}\right)_{3}$ was reacted with either tris(4-bromophenylamine), thianthrene or a small amount of ferrocene to generate $\left[\mathrm{Cp}_{2} \mathrm{Fe}\right]^{+}\left[\mathrm{TCNQ} \cdot 4 \mathrm{~B}\left(\mathrm{C}_{6} \mathrm{~F}_{5}\right)_{3}\right]^{-}$. In the first two cases EPR spectra showed the presence of two radical species each: the corresponding, well-known radical cations as well as the desired radical anion. In the last case only the spectrum of $\left[T C N Q \cdot 4 \mathrm{~B}\left(\mathrm{C}_{6} \mathrm{~F}_{5}\right)_{3}\right]^{-}$was observed, since ferrocenium is not EPR-active at room temperature. The EPR spectrum of the radical anion [TCNQ.4 $\left.\mathrm{B}\left(\mathrm{C}_{6} \mathrm{~F}_{5}\right)_{3}\right]^{-}$consists of one broad, isotropic signal at $\mathrm{g}_{\text {iso }} \approx 2.002$ which confirms the strong delocalization of the unpaired electron. Hyperfine splitting was not observed due the large number of spincarrying nuclei as well as the presence of isotopomers (natural abundance of ${ }^{10} \mathrm{~B}=20 \%, \mathrm{I}=3$, and ${ }^{11} \mathrm{~B}$ with $80 \%$ abundance and $\mathrm{I}=3 / 2$ ). 
In summary, we report a potent oxidation system from commercially available chemicals that works in non-coordinating organic solvents and is easy to use. The combination of TCNQ with four equivalents of $\mathrm{B}\left(\mathrm{C}_{6} \mathrm{~F}_{5}\right)_{3}$ is able to quantitatively oxidize substrates up to an oxidation potential of $E \approx+0.9 \mathrm{~V}$ and generates large, previously unknown weakly-coordinating anions that are redox-active. The resulting [TCNQ.4 B $\left.\left(\mathrm{C}_{6} \mathrm{~F}_{5}\right)_{3}\right]^{-}$monoanion has still enough oxidation power to oxidize ferrocene to ferrocenium. We are optimistic that similar systems (using cyanocarbons in combination with Lewis acids) could not only be used in molecular chemistry, but will also of interest for the doping of organic polymers.

Gefördert durch die Deutsche Forschungsgemeinschaft (DFG) Projektnummer 387284271 - SFB 1349. Computing time was made available by HPC Service of ZEDAT, FU Berlin. We would like to acknowledge the assistance of the Core Facility BioSupraMol supported by the DFG.

\section{Conflicts of interest}

There are no conflicts to declare.

\section{Notes and references}

1. M. Malischewski, M. Adelhardt, J. Sutter, K. Meyer and K. Seppelt, Science, 2016, 353, 678-682.

2. R. T. Boeré, S. Kacprzak, M. Keßler, C. Knapp, R. Riebau, S. Riedel, T. L. Roemmele, M. Rühle, H. Scherer and S. Weber, Angew. Chem. Int. Ed., 2011, 50, 549-552.

3. N. G. Connelly and W. E. Geiger, Chem. Rev., 1996, 96, 877-910.

4. M. Schmitt, M. Mayländer, J. Goost, S. Richert and I. Krossing, Angew. Chem. Int. Ed., 2021, 60, 14800-14805.

5. P. J. Malinowski and I. Krossing, Angew. Chem. Int. Ed., 2014, 53, 13460-13462.

6. P. J. Malinowski, D. Himmel and I. Krossing, Angew. Chem. Int. Ed., 2016, 55, 9259-9261.

7. P. J. Malinowski, D. Himmel and I. Krossing, Angew. Chem. Int. Ed., 2016, 55, 9262-9266.

8. H. Poleschner and K. Seppelt, Angew. Chem. Int. Ed., 2013, 52, 12838-12842.

9. P. Bertocco, C. Bolli, J. Derendorf, C. Jenne, A. Klein and K. Stirnat, Chem. Eur. J., 2016, 22, 16032-16036.

$10 . \quad$ B. T. King, B. C. Noll, A. J. McKinley and J. Michl, J. Am. Chem. Soc., 1996, 118, 10902-10903.

11. M. Schorpp, T. Heizmann, M. Schmucker, S. Rein, S. Weber and I. Krossing, Angew. Chem. Int. Ed., 2020, 59, 9453-9459.

12. A. L. Farragher and F. M. Page, Trans. Faraday Soc., 1967, 63, 2369-2378.

13. J. S. Miller, A. J. Epstein and W. M. Reiff, Science, 1988, 240, 40-47.

14. J. S. Miller, Chem. Soc. Rev., 2011, 40, 3266-3296.

15. D. Jérome, Chem. Rev., 2004, 104, 5565-5592.

16. D. S. Acker, R. J. Harder, W. R. Hertler, W. Mahler, L. R. Melby, R. E. Benson and W. E. Mochel, J. Am. Chem. Soc., 1960, 82, 6408-6409.
17. L. R. Melby, R. J. Harder, W. R. Hertler, W. Mahler, R. E. Benson and W. E. Mochel, J. Am. Chem. Soc., 1962, 84, 3374-3387.

18. B. J. McNicholas, R. H. Grubbs, J. R. Winkler, H. B. Gray and E. Despagnet-Ayoub, Chem. Sci., 2019, 10, 3623-3626.

19. G. Erker, Dalton Trans., 2005, 1883-1890.

20. F. Focante, P. Mercandelli, A. Sironi and L. Resconi, Coord. Chem. Rev., 2006, 250, 170-188.

21. H. Jacobsen, H. Berke, S. Döring, G. Kehr, G. Erker, R. Fröhlich and O. Meyer, Organometallics, 1999, 18, 17241735.

22. R. J. Kwaan, C. J. Harlan and J. R. Norton, Organometallics, 2001, 20, 3818-3820.

23. S. A. Cummings, M. limura, C. J. Harlan, R. J. Kwaan, I. V. Trieu, J. R. Norton, B. M. Bridgewater, F. Jäkle, A. Sundararaman and M. Tilset, Organometallics, 2006, 25, 1565-1568.

24. E. J. Lawrence, V. S. Oganesyan, G. G. Wildgoose and A. E. Ashley, Dalton Trans., 2013, 42, 782-789.

$25 . \quad$ L. L. Liu, L. L. Cao, Y. Shao and D. W. Stephan, J. Am. Chem. Soc., 2017, 139, 10062-10071.

26. X. Tao, C. G. Daniliuc, R. Knitsch, M. R. Hansen, H. Eckert, M. Lübbesmeyer, A. Studer, G. Kehr and G. Erker, Chem. Sci., 2018, 9, 8011-8018.

$27 . \quad$ B. L. Thompson and Z. M. Heiden, Phys. Chem. Chem. Phys, 2021, 23, 9822-9831

28. J. T. Henthorn and T. Agapie, Angew. Chem. Int. Ed., 2014, 53, 12893-12896.

29. R. Choukroun, C. Lorber, D. de Caro and L. Vendier, Organometallics, 2006, 25, 4243-4246.

30. T. A. Hudson and R. Robson, Cryst. Growth Des., 2009, 9, 1658-1662.

31. G.-Z. Zhu and L.-S. Wang, J. Chem. Phys., 2015, 143, 221102.

32. I. C. Vei, S. I. Pascu, M. L. H. Green, J. C. Green, R. E. Schilling, G. D. W. Anderson and L. H. Rees, Dalton Trans., 2003, 2550-2557.

33. M. Lehmann, A. Schulz and A. Villinger, Angew. Chem. Int. Ed., 2009, 48, 7444-7447.

34. H. Heise, F. H. Köhler, M. Herker and W. Hiller, J. Am. Chem. Soc., 2002, 124, 10823-10832.

35. T. Nunes, A. Vainrub, M. Ribet, F. Rachdi, P. Bernier and M. Almeida, J. Chem. Phys., 1992, 96, 8021-8025.

Electronic supplementary information (ESI) available.

CCDC 2133128, 2133132, 2133133, 2133134 